\title{
Panorama das atividades de Educação Ambiental em Unidades de Conservação: uma revisão sistemática em meta-análise
}

\author{
Overview of Environmental Education activities in protected areas: a systematic review meta-analysis
}

Cláudia Regina Bosa', Ana Lucia da Costa²

' Bióloga, Zoológico Municipal de Curitiba.

${ }^{2}$ Bióloga , Pontifícia Universidade Católica do Paraná.

\begin{abstract}
Resumo
Devido aos grandes desafios ambientais da última década a Educação Ambiental vem ganhando destaque e maior atenção por parte da sociedade, como um importante agente transformador da realidade. O presente estudo teve como objetivo realizar uma revisão sistemática em meta-análise na tentativa de conhecer os programas de Educação Ambiental desenvolvidos em Unidades de Conservação no Brasil. O levantamento de dados foi realizado por meio da busca de artigos científicos, obedecendo a um fluxograma previamente delineado. Os pontos de interesse dos artigos selecionados foram: tema do estudo, autores, local de realização, metodologia, público alvo e resultados. Um total de 20 artigos foi selecionado dentro dos parâmetros estabelecidos. Diante da análise dos mesmos foi possível observar a existência de grande número de Unidades de Conservação no Brasil, porém as mesmas não estão distribuídas de forma homogênea, há uma maior distribuição nas regiões sul, sudeste e nordeste, com maior densidade de artigos científicos publicados nas Unidades de Conservação da região sudeste. Diante dos resultados desta revisão, pode-se afirmar que há maior necessidade de criação de Unidades de Conservação nas regiões Norte e Centro-oeste do Brasil e também há necessidade de realizar um trabalho de incentivo para compor equipes de Educação Ambiental em todas as Unidades de Conservação a fim de informar e sensibilizar a população sobre a importância destes ambientes para a conservação dos ecossistemas nos quais estão inseridos.
\end{abstract}

Palavras-chaves: Meio ambiente; Biodiversidade; Educação ao ar livre.

\begin{abstract}
Due to the great environmental challenges of the last decade Environmental Education has been gaining more attention from society as an important agent of transformation of reality. This study aimed to perform a systematic review meta-analysis in an attempt to meet the Environmental Education programs developed in protected areas in Brazil. The survey was conducted through literature search, following a previously outlined flowchart. Nearby points of interest of the selected articles were subject of this study, authors, event location, methodology, target and results. A total of 20 articles were selected within the established parameters. Based on the analysis of the same was possible to observe the existence of a large number of protected areas in Brazil, but the same are not distributed evenly, there is a greater distribution in the south, southeast and northeast, with the highest density of scientific articles published in Conservation Units of Southeastern. Given the results of this review, it can be stated that there is a greater need for the creation of Conservation Units in the North and Midwest regions of Brazil and there is also need for a work incentive for teams composed of Environmental Education in all Units Conservation in order to inform and sensitize the population about the importance of such environments for the conservation of ecosystems in which they live.
\end{abstract}

Keywords: Environment; Biodiversity; Outdoor Education. 


\section{INTRODUÇÃO}

Os debates sobre as questões ambientais são cada vez mais constantes. A partir do momento em que as pessoas dos mais variados setores da sociedade e de diversos lugares do mundo, vivenciam rotineiramente uma cultura de consumismo exacerbado, abuso do extrativismo e consequente descaso com as questões ambientais, passa-se a procurar respostas que amenizem esse tipo de problema. Gonçalvez (1990) define Educação Ambiental como:

O processo de reconhecer valores e aclarar conceitos para criar habilidades e atitudes necessárias que sirvam para compreender e apreciar a relação mútua entre o ser humano, sua cultura e seu meio circundante biofísico. A Educação Ambiental também incluiu a prática de tomar decisões e auto-formular um código de comportamento com relação às questões que concernem à qualidade ambiental.

De acordo com Bezerra (2007), a preocupação em discutir os problemas relacionados ao meio ambiente e à preservação dos aspectos naturais do planeta surgiu a partir da década de quarenta, por meio de alguns eventos internacionais que se destacaram em defender a Educação Ambiental como estratégia na preservação da natureza, foram eles: a Conferência de Estocolmo (1972); a Conferência Internacional de Belgrado (1975); a Conferência Internacional de Tbilisi (1977); e a Conferência Internacional de Moscou (1987).

Em nível nacional, a Conferência das Nações Unidas para o Meio Ambiente e Desenvolvimento, realizada no Rio de Janeiro em 1992, levantou discussões sobre as questões ambientais por todo o Brasil. As informações sobre essa produção começaram a circular, aumentando o interesse pela sua fundamentação política e pedagógica, sendo que foram elaboradas políticas públicas relacionadas com a Educação Ambiental, as quais colocaram em evidência a urgência de pesquisas (Reigota, 2007).

A partir disso, foram inúmeras as dissertações de mestrado, teses de doutorado, monografias de especialização e livros publicados relacionados às questões ambientais e à Educação Ambiental (Fuchs \& Paim, 2010). Diante dessa grande quantidade de estudos verifica-se a necessidade de uma revisão sistemática dos trabalhos realizados, a fim de analisar quais os pontos que apresentam muitos estudos e quais áreas ainda carecem de maior atenção dos pesquisadores em Educação Ambiental.

De acordo com Castro, 2001:

A revisão sistemática é uma revisão planejada para responder a uma pergunta específica e que utiliza métodos explícitos e sistemáticos para identificar, selecionar e avaliar criticamente os estudos, e para coletar e analisar os dados destes estudos incluídos na revisão. A meta-análise, ou metanálise ou ainda, metaanálise é o método utilizado na revisão sistemática para integrar os resultados dos estudos incluídos.

Para Luiz, 2002:

Uma meta-análise visa extrair informação adicional de dados preexistentes através da união de resultados de diversos trabalhos e pela aplicação de uma ou mais técnicas estatísticas. É um método quantitativo que permite combinar os resultados de estudos realizados de forma independente (geralmente extraídos de trabalhos publicados) e sintetizar as suas conclusões ou mesmo extrair uma nova conclusão (...). Praticamente qualquer técnica de análise estatística poderá ser aplicada em meta-análise, dependendo apenas da natureza dos dados e dos objetivos do estudo.

O termo meta-análise, segundo citação de Finney (1995) no artigo de Luiz (2002), foi utilizado pela primeira vez por G.V. Glass, em 1976, em um artigo intitulado "Primary, secondary and meta -analysis of research", na revista Educational Research. A utilização desse termo surgiu juntamente com a necessidade realizar esse método de revisão sistemática em diversas áreas do conhecimento. 
A popularidade no uso da meta-análise teve um grande aumento nas últimas décadas, possivelmente devido à grande explosão de informações pela qual o mundo contemporâneo tem passado, especialmente no mundo científico ou acadêmico (Luiz, 2002).

Segundo Luiz (2002), além do grande crescimento na quantidade de publicações e de trabalhos publicados, o aumento significativo na velocidade da divulgação dos trabalhos via internet é um fator importante na necessidade de realizar análises mais detalhadas desses estudos. Com o desenvolvimento dos recursos eletrônicos e computacionais, se torna possível uma maior facilidade do poder de aquisição, armazenamento, transporte e análise de dados na forma digital, o que, obviamente, influencia na decisão de alguns cientistas em "re-analisarem" ou "superanalisarem" conjuntos de dados ou resultados já disponíveis ao invés de obterem seus próprios dados.

Devido a esse conjunto de fatores, quando se fala em Educação Ambiental, surgem diversos estudos, debates e discussões sobre o tema, baseados nos mais diversos ambientes de estudo, já que ela pode ser trabalhada dentro do ambiente escolar, profissional ou até mesmo no ambiente pessoal/ particular. Inúmeros são os estudos, nacionais e internacionais, que tratam da Educação Ambiental como uma estratégia de preservação do meio ambiente e conscientização por meio da análise crítica sobre as questões ambientais do planeta (Vasco, Zakrzevski \& Valduga, 2007).

Neste trabalho, o foco da Educação Ambiental são as Unidades de Conservação Brasileiras. Unidades de Conservação, ou UC's - áreas de proteção ambiental regidas pelo Sistema Nacional de Unidades de Conservação - SNUC, o qual define e regulamenta as unidades de conservação em nível municipal, estadual e federal, separando-as em Unidades de Proteção Integral e Áreas de Uso Sustentável. O que difere esses dois grupos é que em unidades de proteção integral, como diz o próprio nome, procura-se a total conservação da biodiversidade, enquanto nas áreas de uso sustentável podem ser utilizados os recursos naturais, tendo a conservação da biodiversidade como objetivo secundário (Rylands \& Brandon, 2005).

Segundo Antunes, Coelho \& Jochem (2006), as Unidades de Proteção Integral constituem as estações ecológicas, reservas biológicas, parques nacionais, monumentos naturais e os refúgios de vida silvestre. Já as Unidades de Uso Sustentável constituem as áreas de proteção ambiental e de relevante interesse ecológico: florestas nacionais, reservas extrativistas, reservas de fauna, reservas de desenvolvimento sustentável e as reservas particulares do patrimônio natural.

O presente estudo teve como objetivo mapear artigos científicos que abordassem a Educação Ambiental e suas técnicas em unidades de conservação localizadas no Brasil, a fim de verificar que tipos de estudos são realizados. Para isso, utilizou-se de uma revisão sistemática baseada nos conceitos da meta-análise, com revisão bibliográfica e seleção de artigos.

\section{METODOLOGIA}

O trabalho realizado foi baseado numa revisão sistemática em meta-análise, de acordo com Castro (2001), que tomou como base publicações da Colaboração Cochrane (2000) e NHS Centre for Reviews and Dissemination (2000).

Os passos para uma revisão sistemática baseiam-se, inicialmente, na formulação de uma pergunta ou problema. Nesse estudo, a questão a ser respondida compreendeu o mapeamento de estudos sobre Educação Ambiental realizados em Unidades de Conservação. Após, localizados e selecionados alguns estudos referentes ao tema, os mesmos foram identificados como relevantes por meio de pesquisas pelas bases de dados eletrônicas (principalmente obtidos em banco de teses da CAPES), além de consulta manual em revistas indexadas. Nessa etapa, os critérios para localização dos estudos tiveram foco em artigos que foram publicados, excluindo-se a análise de monografias e teses (Fig.1).

Depois de selecionados os estudos foram lidos e avaliados. Estudos com resultados semelhantes foram agrupados para meta-análise e seus dados interpretados de acordo com a aplicabilidade e viabilidade dos mesmos.

Um total de 20 artigos selecionados foi analisado, para posteriormente compor uma análise total do que foi encontrado, de acordo com os conceitos da meta-análise. Os estudos foram avaliados e explicitados de acordo com os seguintes quesitos: identificação do estudo, autores, local de realização, método para atingir a Educação Ambiental, público alvo e resultados obtidos. 


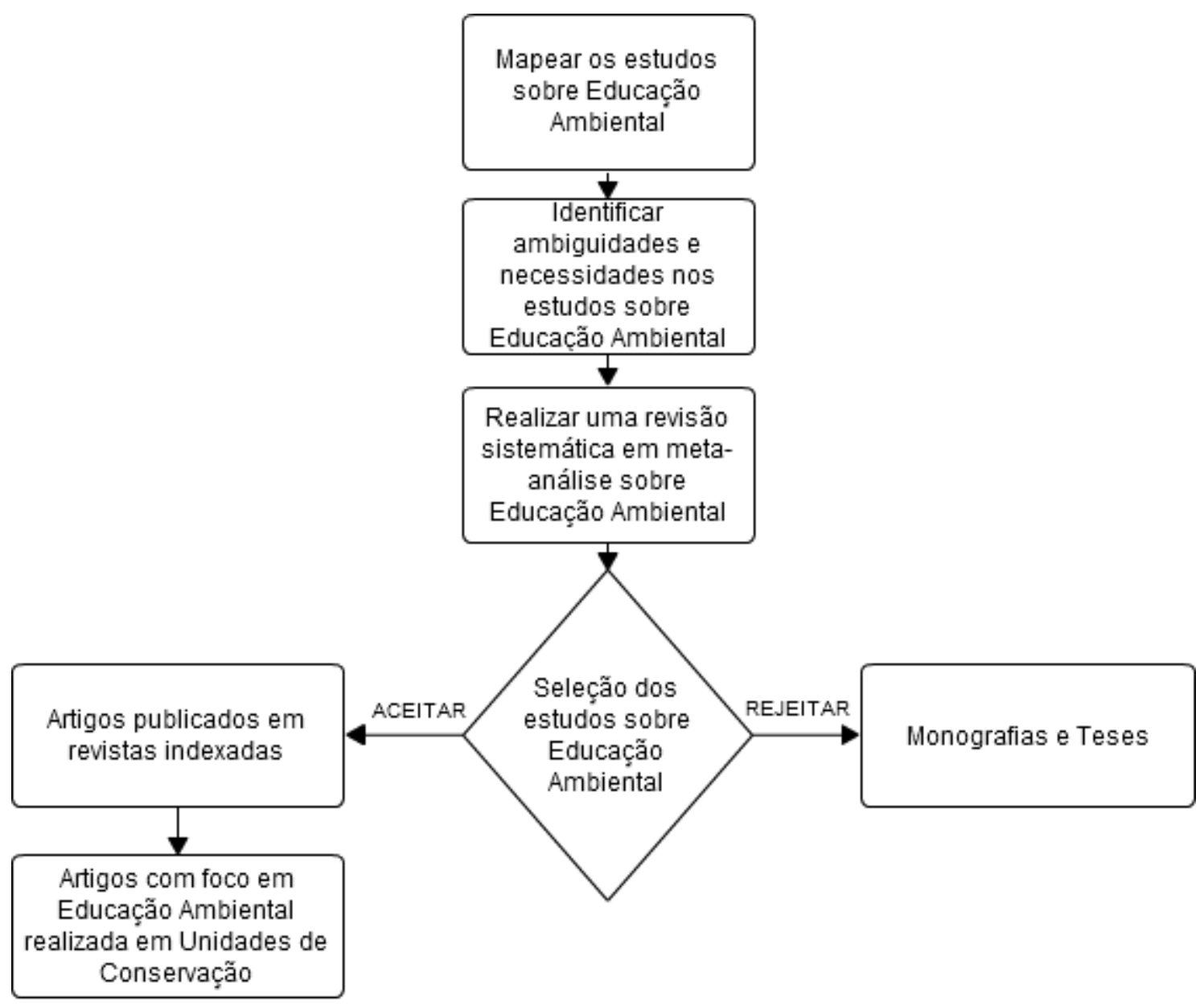

Figura 1. Fluxograma explicitando o processo metodológico utilizado e elaborado neste trabalho.

\section{RESULTADOS E DISCUSSÃO}

A seguir estão listados os artigos selecionados para análise dos trabalhos de Educação Ambiental em Unidades de Conservação:

\section{Educação Ambiental no Acantonamento Ecológico, Curitiba, Paraná.}

a) Local de realização: Zoológico Municipal de Curitiba, Curitiba, Paraná, Brasil.

b) Autores: BOSA, Cláudia Regina; SOBOTA, Andressa.

c) Método utilizado: Aplicação de dois questionários - um pré-teste, (aplicado antes da realização do Acantonamento Ecológico na escola de origem) e outro pós-teste (aplicado no final do Acantonamento Ecológico).

d) Público alvo: Alunos do $5^{\circ}$ ano da Rede Municipal de Ensino de Curitiba.

e) Resultados: O objetivo final foi atingido, mostrando que os alunos compreenderam os conceitos que envolvem a Educação Ambiental e suas vertentes. $O$ resultado adquirido pode demonstrar que o conhecimento conquistado será passado adiante pelos alunos.

2. Etnobotânica e etnozoologia em unidades de conservação: uso da biodiversidade na APA de Genipabu, Rio Grande do Norte, Brasil.

a) Local de realização: APA de Genipabu, Rio Grande do Norte, Brasil.

b) Autores: TORRES, Denise F.; OLIVEIRA, Eduardo S.; ALVES, Romulo R. N.; VASCON- 
CELLOS, Alexandre.

c) Método utilizado: Questionários sobre percepção da área, conhecimento sobre a biodiversidade e seus eventuais usos.

d) Público alvo: Moradores das comunidades da APA-Genipabu.

e) Resultados: A maioria dos entrevistados não conhece os objetivos de uma APA, mas reconheceram a biodiversidade do local e a necessidade de sua preservação.

\section{Parque Municipal Victório Siquierolli: um novo olhar sobre educação ambiental}

a)Local de realização: Núcleo de Educação Ambiental (NEA) do Parque Municipal Victório Siquierolli, Minas Gerais, Brasil.

b) Autores: GONÇALVES, Fredston C.; OLIVEIRA, Ana C. M.

c) Método utilizado: Análise documental, referencial teórico, entrevistas e observações diretas.

d) Público alvo: Crianças, jovens e adultos.

e) Resultados: As atividades desenvolvidas revelaram que o NEA tem ótima qualidade e consegue interferir positivamente na percepção dos visitantes sobre a educação ambiental.

4. A importância da educação ambiental em unidades de conservação: experiência do centro de referência em educação ambiental de Marapendi

a) Local de realização: Parque Natural Municipal de Marapendi, Rio de Janeiro, Brasil.

b) Autores: ANTUNES, Karen G.; COELHO, Rodrigo; JOCHEM, Tania.

c) Método utilizado: Realização de visitas orientadas, cursos e palestras sobre Meio Ambiente e Educação Ambiental e oficinas de reaproveitamento (projetos como: "aluno guardião da orla" e "horta no parque plantando esperança")

d) Público alvo: Crianças, jovens e adultos.

e) Resultados: o Parque possui um Centro de Educação Ambiental (CEA) específico para realizar as atividades. Isso atraiu cada vez mais a população para dentro da unidade de conservação, apresentando suas características, problemas e importância ecológica.

5. Educação ambiental aplicada ao ecoturismo nas unidades de conservação do polo de ecoturismo da Ilha de Santa Catarina

a) Local de realização: Pólo de Ecoturismo da Ilha de Santa Catarina (PEISC), Santa Catarina, Brasil.

b) Autores: BUENO, Fernando Protti.

c) Método utilizado: Ecoturismo

d) Público alvo: Crianças, jovens e adultos.

e) Resultados: Existe uma relação simultânea na aplicação das modalidades de educação ambiental no ecoturismo, pois os dois são ferramentas que complementam o outro e atingem o objetivo maior que é a conservação daquele ambiente.

6. Percepção ambiental e conflitos de uso dos recursos naturais - um estudo na APA do Sistema Cantareira, São Paulo, Brasil.

a) Local de realização: Área de Proteção Ambiental (APA) do Sistema Cantareira, São Paulo, Brasil.

b) Autores: HOEFFEL, João L.; FADINI, Almerinda A. B.; MACHADO, Micheli K.; REIS, Jussara C. R.

c) Método utilizado: Ecoturismo

d) Público alvo: Moradores locais e turistas.

e) Resultados: Os grupos sociais regionais apresentaram diferentes percepções sobre meio ambiente e desenvolvimento, o que gera diversos impactos na APA Cantareira e também não existem planos regionais participativos que apontem soluções efetivas para os problemas sócio -ambientais encontrados. 
7. Percepção ambiental em unidades de conservação: experiência com diferentes grupos etários no Parque Estadual da Serra do Rola Moça, MG.

a) Local de realização: Parque Estadual da Serra do Rola Moça, Minas Gerais, Brasil.

b) Autores: JACOBI, Claudia M.; FLEURY, Lorena C.; ROCHA, Ana C. C. L.

c) Método utilizado: Palestras, visitação a trilhas e avaliação por meio de questionário.

d) Público alvo: Crianças, jovens e adultos.

e) Resultados: Os resultados evidenciam a importância de visitas guiadas para melhor rendimento da atividade e a valiosa ferramenta que as UC's representam no processo da construção do conhecimento ecológico e ambiental.

8. Unidade de conservação e educação ambiental: um estudo sobre o perfil dos visitantes no local.

a) Local de realização: Parque da Lajinha, Minas Gerais, Brasil.

b) Autores: LUZ, Noemi S.; EVELING, Oceli S.; MORAIS, Robson B.; ZACARIAS, Rachel.

c) Método utilizado: Plano de Manejo

d) Público alvo: Crianças, jovens e adultos.

e) Resultados: Ocorrem falhas na aplicação das atividades de educação ambiental, pois o parque não está bem conservado. Não há um preparo adequado e específico na educação ambiental do local.

9. Biodiversidade e conservação dos recursos naturais da área de proteção ambiental (APA) do Engenho Pequeno, São Gonçalo, RJ.

a) Local de realização: Área de proteção ambiental (APA) do Engenho Pequeno, Rio de Janeiro, Brasil.

b) Autores: SANTOS, M. G. et al.

c) Método utilizado: atividades que visem capacitar alunos de todos os segmentos e a comunidade local numa maior integração com o meio ambiente.

d) Público alvo: Crianças, jovens e adultos.

e) Resultados: Buscou-se uma melhora na conservação da APA, já que as atividades são apenas propostas e não aplicadas na prática.

10. Educação ambiental em unidades de conservação: um estudo de caso na área de proteção ambiental de Sousas e Joaquim Egídio.

a) Local de realização: APA de Sousas e Joaquim Egídio, São Paulo, Brasil.

b) Autores: VENDRAMETTO, Lilian P.

c) Método utilizado: Entrevistas semi-estruturadas, questionários, análise documental e realização de oficinas.

d) Público alvo: Alunos da $7^{a}$ série da rede municipal de ensino.

e) Resultados: Os alunos tiveram uma percepção melhor do local que habitavam e de como cuidavam daquilo, passando a ter mais atenção com as questões ambientais, se sentindo parte do meio ambiente e atuando diretamente na sua conservação.

11. Área de proteção ambiental municipal do Bororé-Colônia, São Paulo (SP): potencial para práticas de educação ambiental e ecoturismo.

a) Local de realização: APA de Bororé-Colônia, São Paulo, Brasil.

b) Autotes: ROCHA, L.; MAIQUE, E. T.; ABREU, F. S. B.; CASTRO, J. R. S.; OLIVEIRA, M. T. C.

c) Método utilizado: Ecoturismo

d) Público alvo: Crianças, jovens e adultos.

e) Resultados: Embora verificada a presença de uma empresa de turismo, não foram identifi- 
cadas ações para melhoria da qualidade socioambiental da região induzidas pela atividade de ecoturismo, colaborando para preservar o patrimônio natural e a biodiversidade, bem como a promoção de atividades para trazer benefícios à comunidade local e das atividades educativas com os moradores inseridos na área.

12. Ecoturismo e educação ambiental no cerrado paulista: diagnóstico das condições de uso público do Parque Estadual Do Juquery, Caieiras e Franco Da Rocha (SP).

a) Local de realização: Parque Estadual Do Juquery, Caieiras e Franco Da Rocha, São Paulo, Brasil.

b) Autores: ALVES, Patricia A. G.; OLIVEIRA, Marcelo T. C.

c) Método utilizado: Ecoturismo, museu com exposições sobre a fauna e flora local, trilhas abertas.

d) Público alvo: Principalmente crianças e jovens.

e) Resultados: Tem potencial para o Ecoturismo, mas não sabe como utilizar por falta de estrutura e de instrução de monitores responsáveis pelas atividades de educação ambiental.

13. Planejamento e educação ambiental do ecoturismo no Parque Estadual da Pedra da Boca, Araruna/PB.

a) Local de realização: Parque Estadual da Pedra da Boca, Paraíba, Brasil.

b) Autores: CAVALCANTE, M.; FURTADO, Edna M.

c) Método utilizado: Ecoturismo

d) Público alvo: Turistas e moradores do entorno do Parque.

e) Resultados: Verificou-se uma mudança nas atitudes e comportamentos do público no que se refere a sua co-participação na gestão e planejamento do ecoturismo local, bem como na preservação os recursos naturais e sociais do lugar.

14. Observação de aves: uma ferramenta de educação ambiental no Parque Estadual Cantareira.

a) Local de realização: Parque Estadual Cantareira, São Paulo, Brasil.

b) Autores: LARANJA, Diego H. R.

c) Método utilizado: Aulas experimentais com alunos de escolas visitantes do Parque, aplicando atividades antes e após a visita como, observação de aves, objetivando identificar os conceitos que os mesmos sabiam sobre meio ambiente e biodiversidade.

d) Público alvo: Principalmente crianças e jovens.

e) Resultados: Mostram que a unidade de conservação possui grande importância ecológica e potencial para a realização da atividade de observação de aves, podendo ser utilizada no desenvolvimento do ecoturismo e atividades educativas para escolas do entorno da unidade.

15. Ecoturismo e educação ambiental no contexto da baixada fluminense: um diagnóstico das escolas do entorno do Parque Natural Municipal De Nova Iguaçu (RJ).

a) Local de realização: Parque Natural Municipal De Nova Iguaçu, Rio de Janeiro, Brasil.

b) Autores: MACHADO, Márcia L. F.; COSTA, Nadja M.C.

c) Método utilizado: Ecoturismo

d) Público alvo: Crianças, jovens e adultos.

e) Resultados: Houve falta de suporte material nas atividades de campo, o Plano de Manejo do parque é pouco conhecido e a comunidade local que fica no entorno do parque não vê o ambiente como importante para vivenciar práticas de educação ambiental.

\section{A Educação Ambiental através do contato dirigido com a natureza.}

a) Local de realização: Parque Estadual Turístico do Alto Ribeira (PETAR), São Paulo, Brasil. 
b) Autores: NEIMAN, Zysman.

c) Método utilizado: Visita dirigida ao PETAR, aplicação de questionários.

d) Público alvo: Jovens e adultos.

e) Resultados: Ao abordar o ecoturismo nessa unidade, foi importante perceber que a visita dirigida não se resumiu a "levar" as pessoas para a natureza, mas proporcionou que as mesmas "percebessem" a natureza ao redor delas.

\section{O professor e o ensino de ciências no jardim zoológico.}

a) Local de realização: Jardim Zoológico da Fundação Zoo-Botânica de Belo Horizonte, Minas Gerais, Brasil.

b) Autores: MENEGAZZI, Cristiane S.

c) Método utilizado: Análise da relação professor-aluno em visitas ao zoológico.

d) Público alvo: Professores e alunos.

e) Resultados: Foi possível perceber que o zoológico é um espaço integrador no ensino de ciências, mas que ainda há muitos fatores que fazem o docente fugir do seu objetivo principal num espaço não formal de ensino. Porém, a autora defende que esse tipo de atividade faz a diferença no aprendizado do aluno.

\section{O zoológico como espaço integrador de posturas em educação ambiental.}

a) Local de realização: Zoológico Municipal de São José do Rio Preto, São Paulo, Brasil.

b) Autores: RAMOS, Vanessa N.; VARELLA, Marco A. C.; ANTONIO, Mariana R.; PERIOTTO, Natalia A.

c) Método utilizado: Elaboração de material didático e mini-cursos para estudantes de Biologia e funcionários do Zoológico.

d) Público alvo: Estudantes de biologia e funcionários do zoológico.

e) Resultados: Partindo dos funcionários para nortear as discussões, criou-se, pelo conhecimento sobre sua própria prática, um sentimento de respeito e responsabilidade pelas questões ambientais. Esse sentimento, junto ao conhecimento que o gerou, pode se tornar um valor incorporado e orientar atitudes em outros contextos. A conscientização sobre o fazer, juntamente com a estruturação de como fazer, isto é, o conhecimento, é um dos primeiros passos para a efetivação das ações em educação ambiental.

19. Análise do potencial pedagógico de espaços não formais de ensino para o desenvolvimento da temática da biodiversidade e sua conservação.

* Este estudo foi aplicado em mais de uma unidade de conservação.

a) Local de realização: Parque Ecológico Voturuá, São Vicente; Jardim Boânico Chico Mendes, Santos; Museu de Pesca, Santos; Acqua Mundo, Guarujá; todos localizados no litoral de São Paulo, Brasil.

b) Autores: PIVELLI, Sandra R. P.

c) Método utilizado: Foi realizada observação dos espaços, análise de material didático/ pedagógico, questionários e entrevistas realizadas com os profissionais de cada unidade e que atuam na educação ambiental.

d) Público alvo: Profissionais de cada uma das unidades de conservação.

e) Resultados: Todas as unidades apresentam em comum um grande potencial para desenvolver a educação ambiental quando ao aspecto expositivo. Porém, o entretenimento é visto como a principal atividade, que acaba por deixar a busca pelo conhecimento das questões ambientais como algo a parte das visitas aos parques.

20. Educação ambiental não formal em unidades de conservação federais na zona costeira brasileira: uma análise crítica

* Este estudo foi aplicado em mais de uma unidade de conservação.

a) Local de realização: Parque Nacional da Lagoa do Peixe, Rio Grande do Sul; Reserva Bio- 
lógica do Arvoredo, Santa Catarina; Área de Proteção Ambiental de Guaraqueçaba, Paraná; Reserva Biológica de Comboios, Espírito Santo; Reserva Biológica de Santa Isabel, Sergipe; Área de Proteção Ambiental de Mamanguape, Paraíba, Brasil.

b) Autores: MADUREIRA, Marta S. P.; TAGLIANI, Paulo R. A.

c) Método utilizado: questionários respondidos pelos responsáveis de cada unidade de conservação com questões referentes aos aspectos funcionais da entidade e a aspectos conceituais, tendo-se visitado algumas unidades de conservação para observações.

d) Público alvo: Funcionários responsáveis por cada unidade de conservação.

e) Resultados: Os programas de educação ambiental nessas unidades ocorrem principalmente com escolas e com a comunidade que vive no entorno desses ambientes. Porém, o resultado desses programas foi abaixo do esperado, pois há carência de recursos para que isso se desenvolva de maneira eficaz, sendo o fator econômico muito importante no setor da educação ambiental, onde se precisa de uma estrutura concreta para desenvolver as atividades. Portanto, nesse estudo os autores analisaram uma falta de apoio financeiro para a educação ambiental.

Após análise dos artigos selecionados, os mesmos foram plotados em um mapa do Brasil, a fim de facilitar a visualização da ocorrência dos mesmos (Fig. 2a). Em seguida, o primeiro mapa foi comparado ao mapa que referencia as Unidades de Conservação existentes no Brasil (Fig. 2b).
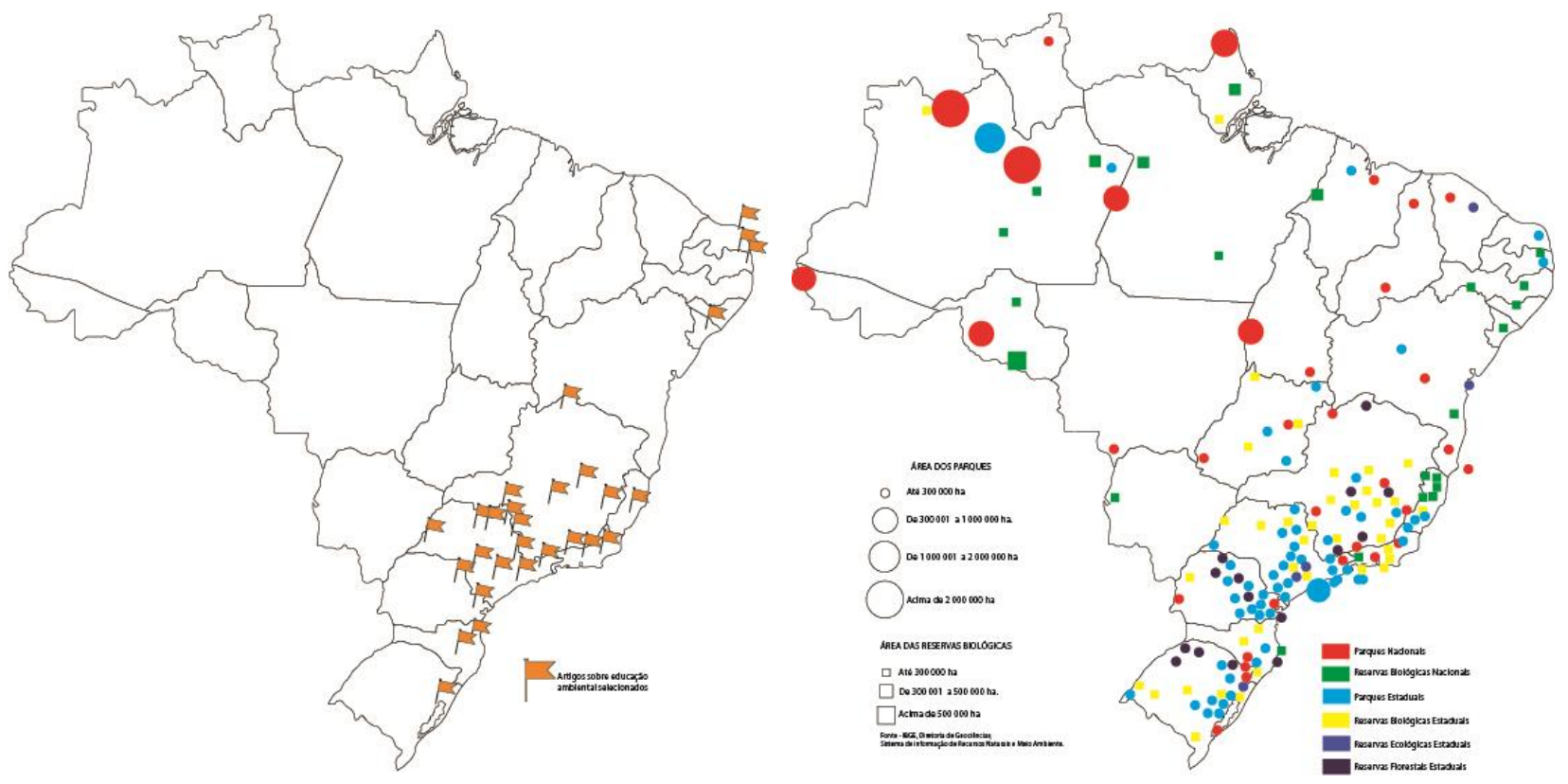

Figura 2 - 2a. Mapa que representa a distribuição dos artigos selecionados para a meta-análise sobre Educação Ambiental nas Unidades de Conservação brasileiras. 2b. Mapa que representa a distribuição das Unidades de Conservação brasileiras.

Fonte: IBGE.

Por fim, foi realizada a junção dos dois mapas (Fig. 3) para contrastar a quantidade de estudos realizados com a distribuição das Unidades de Conservação.

Por meio da análise das figuras, verificou-se uma maior distribuição de Unidades de Conservação nas regiões Sudeste e Sul do Brasil, bem como o maior número dos estudos realizados nestes ambientes relacionados à prática de atividades em Educação Ambiental. O Estado de São Paulo merece destaque para a produção de artigos científicos com este perfil. Também foram observadas regiões onde há Unidades de Conservação, porém nenhum artigo científico foi encontrado. Diante do número de Unidades de Conservação existentes no Brasil, acredita-se que um maior volume de publicações científicas poderia ser encontrado, o que não foi o caso.

Após a leitura e análise crítica dos artigos foi possível verificar que vários tipos de atividades em Educação Ambiental são desenvolvidos em Unidades de Conservação, para diferentes grupos de pessoas e com boa aceitação pelo público visitante. Reforça-se neste artigo a importância de que pro- 
gramas de Educação Ambiental sejam desenvolvidos em todas as Unidades de Conservação a fim de sensibilizar de forma efetiva seus visitantes.

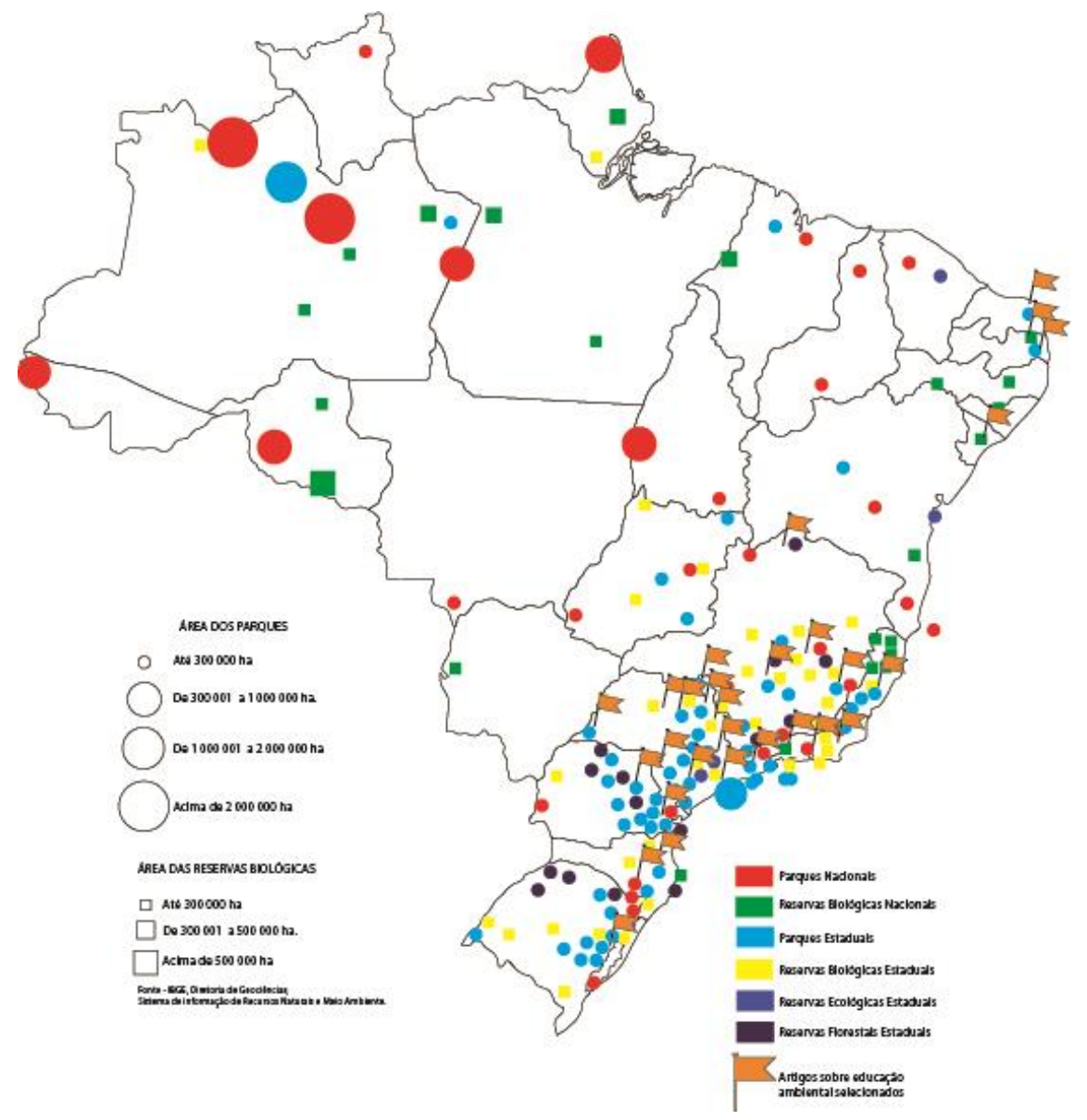

Figura 3. Mapa que representa a distribuição das Unidades de Conservação e dos artigos selecionados no estudo.

A análise dos 20 artigos selecionados demonstrou que, de forma geral, a Educação Ambiental aplicada em Unidades de Conservação é bem sucedida, aplicada a diversos públicos e em diferentes localidades do país. Outro fato é que o Ecoturismo está em ascensão, onde podem ser exploradas atividades que envolvem os mais variados públicos (crianças, jovens, adultos) e em diferentes espaços - escaladas, trilhas, observação de fauna e flora, esportes aquáticos, entre outros. Porém, é importante ressaltar que ele além de entreter o público e ser utilizado principalmente por lazer, pode e deve ser mais explorado como uma ferramenta nas práticas de Educação ambiental de contemplação e respeito à natureza.

Outro importante ponto analisado é a diferente visão dos autores, onde alguns analisaram aspectos estruturais, outros conceituais e até mesmo pedagógicos ou ambientais nas Unidades de Conservação em questão. É importante ressaltar que a união dos resultados de cada um desses fatores, pode favorecer o futuro das práticas de Educação Ambiental em Unidades de Conservação.

As Unidades de Conservação são ótimos espaços para o desenvolvimento e aprimoramento da Educação Ambiental. Espera-se o aumento de publicações que mostrem a importância destes ambientes para o desenvolvimento de programas de Educação Ambiental, a fim de garantir uma maior conscientização por parte da população na conservação da biodiversidade. Unidades de Conservação são a chave para conservar o que ainda resta (Rylands \& Brandon, 2005). Trabalhos em Educação Ambiental, voltados especificamente para as pessoas que vivem no entorno das Unidades de Conservação e também para os visitantes destas unidades, podem trazer bons resultados e consolidar no saber dos indivíduos a necessidade destes espaços em termos ambientais e culturais. 


\section{REFERÊNCIAS}

Alves, P. A. G. \& Oliveira, M. T. C (2011). Ecoturismo e educação ambiental no cerrado paulista: diagnóstico das condições de uso público do Parque Estadual Do Juquery, Caieiras e Franco Da Rocha (SP). Revista Brasileira de Ecoturismo, 4(4). Recuperado em 02 de maio de 2011 de http://www.sbecotur.org.br/rbecotur/ seer/index.php/ecoturismo/article/view/282

Amaral, J. A. A. \& Silva, A. M. (2010). Ajustes de metodologia de ensino para atividades de educação ambiental considerando a unidade espacial bacia hidrográfica. Revista de Estudos Ambientais, 12(1). Recuperado em 26 de março de 2012 de http://proxy.furb.br/ojs/index.php/rea/article/view/1579

Antunes, K. G.; Coelho, R. \& Jochem, T. (2006). A importância da educação ambiental em unidades de conservação: experiência do centro de referência em educação ambiental de Marapendi. Recuperado em 02 de maio de 2012 de http://www.ivt-rj.net/sapis/2006/pdf/KarenAntunes.pdf

Bezerra, A. A. (2007) Fragmentos da história da educação ambiental (EA). Recuperado em 22 de julho de 2011 de http://dialogica.ufam.edu.br/PDF/no3/Aldenice_Educacao_ambiental.pdf

Bosa, C. R. \& Sobota, A. (2011). Educação ambiental no acantonamento ecológico, Curitiba, Paraná. Revista Eletrônica do PPGEAmb-CCR/UFSM. Recuperado em 22 de julho de 2011 de http://cascavel.ufsm.br/revistas/ojs-2.2.2/index.php/remoa/article/viewFile/2651/1602

Brandon, K.; Fonseca, G. A. B.; Rylands, A. B. \& Silva, J. M. C. (2005). Conservação brasileira: desafios e oportunidades. Megadiversidade, 1(1). Recuperado em 14 de maio de 2012 de https://library.conservation. org/Published\%20Documents/2009/03_brandom_et_al.pdf

Bueno, F. P. (2008). Educação ambiental aplicada ao ecoturismo nas unidades de conservação do pólo de ecoturismo da Ilha de Santa Catarina. Rev. Eletrônica Mestr. Educ. Ambient, 20, 1517-1256. Recuperado em 02 de maio de 2012 de http://www.remea.furg.br/edicoes/vol20/art6v20.pdf

Castro, A. A. (2001). Revisão sistemática e meta-análise. Recuperado em 22 de julho de 2011 de http://metodologia.org/wp-content/uploads/2010/08/meta1.PDF

Cavalcante, M. B. \& Furtado, E. M. (2011). Planejamento e educação ambiental do ecoturismo no Parque Estadual Da Pedra Da Boca, Araruna (PB). Revista Brasileira de Ecoturismo, 4(4). Recuperado em 02 de maio de 2012 de http://www.sbecotur.org.br/rbecotur/seer/index.php/ecoturismo/article/view/218

Clarke M. \& Oxman Ad. (2000). Cochrane Reviewers' Handbook 4.1. Oxford, England: The Cochrane Collaboration. Recuperado em 11 de agosto de 2011 de http://www.cochrane.dk

Fuchs, S.C. \& Paim, B.S. (2010). Revisão sistemática de estudos observacionais com metanálise. Recuperado em 11 de agosto de 2011 de http://seer.ufrgs.br/hcpa/article/view/16551

Gonçalves, F. C. \& Oliveira, A. C. M. (2009). Parque Municipal Victório Siquierolli: um novo olhar sobre educação ambiental. Caminhos de Geografia, 10(31). Recuperado em 26 de março de 2012 de http://www. seer.ufu.br/index.php/caminhosdegeografia/article/view/10761

Hoeffel, J. L.; Fadini, A. A. B.; Machado, M. K. \& Reis, J. C. (2006). Percepção ambiental e conflitos de uso dos recursos naturais - um estudo na APA do Sistema Cantareira, São Paulo, Brasil. III Encontro da ANPPAS, maio de 2006.

IBGE. (2012). Mapas temáticos. Unidades de Conservação. Recuperado em 14 de maio de 2012 de ftp://ftp. ibge.gov.br/Cartas_e_Mapas/Mapas_Tematicos/

Jacobi, C. M.; Fleury, L. C. \& Rocha, A. C. C. L. (2004). Percepção ambiental em unidades de conservação: 
experiência com diferentes grupos etários no Parque Estadual da Serra do Rola Moça, MG. Anais do $7^{\circ}$ Encontro de Extensão da Universidade Federal de Minas Gerais, Belo Horizonte. Recuperado em 02 de maio de 2012 de http://www.ufmg.br/proex/arquivos/7Encontro/Meio12.pdf

Laranja, D. H. R. (2011). Observação de aves: uma ferramenta de educação ambiental no Parque Estadual Cantareira. Revista Brasileira de Ecoturismo, 4(4). Recuperado em 02 de maio de 2012 de http://www.sbecotur.org.br/rbecotur/seer/index.php/ecoturismo/article/view/232

Luiz, A. J. B. (2002). Meta-análise: definição, aplicações e sinergia com dados espaciais. Cadernos de Ciência \& Tecnologia, Brasília, 19(3), 407-428. Recuperado em 04 de agosto de 2011 de http://webnotes.sct.embrapa. $\mathrm{br} / \mathrm{pdf} / \mathrm{cct} / \mathrm{v} 19 / \mathrm{cc} 19 \mathrm{n} 3$ _03.pdf

Luz, N. S.; Eveling, O. S.; Morais, R. B. \& Zacarias, R. (2005). Unidade de conservação e educação ambiental: um estudo sobre o perfil dos visitantes no local. Recuperado em 02 de maio de 2012 de http://www. viannajr.edu.br/site/menu/publicacoes/publicacao_tecnologos/artigos/edicao1/200615903.pdf

Machado, M. L. F. \& Costa, N. M. C. (2011). Ecoturismo e educação ambiental no contexto da baixada fluminense: um diagnóstico das escolas do entorno do Parque Natural Municipal De Nova Iguaçu (RJ). Revista Brasileira de Ecoturismo, 4(4). Recuperado em 02 de maio de 2012 de http://www.sbecotur.org.br/rbecotur/ seer/index.php/ecoturismo/article/view/226

Madureira, M. S. P. \& Tagliani, P. R. A. (1997). Educação ambiental não-formal em unidades de conservação federais na zona costeira brasileira: uma análise crítica. Recuperado em 02 de maio de 2012 de http://br.monografias.com/trabalhos917/educacao-ambiental-costeira/educacao-ambiental-costeira.shtml

Menegazzi, C. S. (2003). O professor e o ensino de ciências no jardim zoológico. Recuperado em 08 de agosto de 2011 de http://www.bibliotecadigital.ufmg.br/dspace/bitstream/1843/FAEC-8GGMSY/1/dissertacao_ cristiane_speziali_menegazzi_ufmg.pdf

Neiman, Z. (2007). A educação ambiental através do contato dirigido com a natureza. Recuperado em 08 de agosto de $2011 \mathrm{de}$ http://www.physis.org.br/tesezysman.pdf

Pivelli, S. R. P. (2003). Análise do potencial pedagógico de espaços não-formais de ensino para o desenvolvimento da temática da biodiversidade e sua conservação. Recuperado em 08 de agosto de $2011 \mathrm{de} \mathrm{http://www.}$ teses.usp.br/teses/disponiveis/48/48134/tde-22062007-092500/pt-br.php

Ramos, V. N.; Varella, M. A. C.; Antonio, M. R.; Periotto, N. A. \& Goulart, R. R. (2009). O zoológico como espaço integrador de posturas em educação ambiental. Rev. Ciênc. Ext, 5(1), 119. Recuperado em 08 de agosto de 2011 de http://ojs.unesp.br/index.php/revista_proex/article/view/66/70

Reigota, M. (2001). O que é educação ambiental ( $3^{\mathrm{a} e d .}$ ) São Paulo: Brasiliense.

Reigota, M. (2007). O estado da arte da pesquisa em educação ambiental no Brasil. Pesquisa em Educação Ambiental, 2(1), 33-66. Recuperado em 22 de julho de 2011 de http://www.revistasusp.sibi.usp.br/scielo. php?pid=S1980-11652007000100003\&script $=$ sci_abstract\&tlng=ptco

Rocha, L.; Maique, E. T.; Abreu, F. S. B.; Castro, J. R. S. \& Oliveira, M. T. C. (2011). Área de proteção ambiental municipal do Bororé-Colônia, São Paulo (SP): potencial para práticas de educação ambiental e ecoturismo. Revista Brasileira de Ecoturismo, 4(4). Recuperado em 02 de maio de 2012 de http://www.sbecotur. org.br/rbecotur/seer/index.php/ecoturismo/article/view/249

Rylands, A. B.; Brandon, K. (2005). Unidades de conservação brasileiras. Megadiversidade, 1(1). Recuperado em 15 de maio de 2012 de http://www.conservacao.org/publicacoes/files/06_rylands_brandon.pdf

Santos, M. G.; Pinto, L. J. S.; Santos, M. C. F.; Pimentel, D. S.; Jascone, C. E. S.; Laurindo, T. F. S. et al. 
(2004). Biodiversidade e conservação dos recursos naturais da área de proteção ambiental (APA) do Engenho Pequeno, São Gonçalo, RJ. Recuperado em 02 de maio de 2012 de http://lemeambiental.com.br/Biodiversidade $\% 20$ e $\% 20$ conserva $\%$ C3\%A7\%C3\%A3o\%20dos\%20recursos\%20naturais $\% 20$.pdf

Torres, D. F.; Oliveira, E. S.; Alves, R. R. N. \& Vasconcellos, A. (2009). Etnobotânica e Etnozoologia em unidades de conservação: uso da biodiversidade na APA de Genipabu, Rio Grande do Norte, Brasil. Recuperado em 26 de março de 2012 de http://www.scielo.org.ve/pdf/inci/v34n9/art07.pdf

Vasco, A.P.; Zakrzevski, S.B.B \& Valduga, A.(2007). A pesquisa em educação ambiental no Brasil: um estudo dos programas de pós-graduação stricto sensu. Recuperado em 22 de julho de 2011 de http://www.seb-ecologia.org.br/viiiceb/pdf/1428.pdf

Vendrametto, L. P. (2004). Educação ambiental em unidades de conservação: um estudo de caso na área de proteção ambiental de Sousas e Joaquim Egídio. Recuperado em 02 de maio de 2012 de http://www.teses. usp.br/teses/disponiveis/11/11150/tde-06102004-165858/pt-br.php 